Atmos. Chem. Phys., 18, 17489-17496, 2018

https://doi.org/10.5194/acp-18-17489-2018

(C) Author(s) 2018. This work is distributed under

the Creative Commons Attribution 4.0 License.

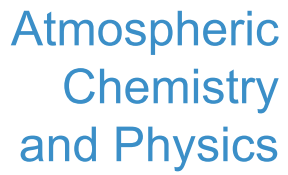

(c) (P)

\title{
Insignificant effect of climate change on winter haze pollution in Beijing
}

\author{
Lu Shen ${ }^{1}$, Daniel J. Jacob ${ }^{1}$, Loretta J. Mickley ${ }^{1}$, Yuxuan Wang ${ }^{2,3}$, and Qiang Zhang ${ }^{3}$ \\ ${ }^{1}$ School of Engineering and Applied Sciences, Harvard University, Cambridge, MA 02138, USA \\ ${ }^{2}$ Department of Earth and Atmospheric Sciences, University of Houston, Houston, TX, USA \\ ${ }^{3}$ Department of Earth System Science, Tsinghua University, Beijing, China
}

Correspondence: Lu Shen (1shen@fas.harvard.edu)

Received: 5 September 2018 - Discussion started: 18 September 2018

Revised: 15 November 2018 - Accepted: 15 November 2018 - Published: 11 December 2018

\begin{abstract}
Several recent studies have suggested that 21st century climate change will significantly worsen the meteorological conditions, leading to very high concentrations of fine particulate matter $\left(\mathrm{PM}_{2.5}\right)$ in Beijing in winter (Beijing haze). We find that $81 \%$ of the variance in observed monthly $\mathrm{PM}_{2.5}$ during 2010-2017 winters can be explained by a single meteorological mode, the first principal component (PC1) of the $850 \mathrm{hPa}$ meridional wind velocity (V850) and relative humidity $(\mathrm{RH})$. V850 and $\mathrm{RH}$ drive stagnation and chemical production of $\mathrm{PM}_{2.5}$, respectively, and thus have a clear causal link to Beijing haze. PC1 explains more of the variance in $\mathrm{PM}_{2.5}$ than either V850 or RH alone. Using additional meteorological variables does not explain more of the variance in $\mathrm{PM}_{2.5}$. Therefore $\mathrm{PC} 1$ can serve as a proxy for Beijing haze in the interpretation of long-term climate records and in future climate projections. Previous studies suggested that shrinking Arctic sea ice would worsen winter haze conditions in eastern China, but we show with the PC1 proxy that Beijing haze is correlated with a dipole structure in the Arctic sea ice rather than with the total amount of sea ice. Beijing haze is also correlated with dipole patterns in Pacific sea surface temperatures (SSTs). We find that these dipole patterns of Arctic sea ice and Pacific SSTs shift and change sign on interdecadal scales, so that they cannot be used reliably as future predictors for the haze. Future 21st century trends of the PC1 haze proxy computed from the CMIP5 ensemble of climate models are statistically insignificant. We conclude that climate change is unlikely to significantly offset current efforts to decrease Beijing haze through emission controls.
\end{abstract}

\section{Introduction}

Severe wintertime haze pollution in Beijing caused by particulate matter finer than $2.5 \mu \mathrm{m}$ aerodynamic diameter $\left(\mathrm{PM}_{2.5}\right)$ is a major threat to public health. Wintertime (December-January-February, DJF) $\mathrm{PM}_{2.5}$ in Beijing averaged $110 \mu \mathrm{g} \mathrm{m}^{-3}$ during 2009-2015 (Cai et al., 2017), more than 4 times the recommended $24 \mathrm{~h}$ standard $\left(25 \mu \mathrm{g} \mathrm{m}^{-3}\right)$ of the World Health Organization (WHO, 2006). This Beijing haze is caused by a combination of high emissions and poor ventilation. The most severe haze events occur during sustained stagnant conditions with high humidity (Y. S. Wang et al., 2014).

Several recent studies (Wang et al., 2015; Cai et al., 2017; Zou et al., 2017; Li et al., 2018) have suggested that climate change will worsen Beijing haze, offsetting the major efforts currently underway to reduce emissions. Wang et al. (2015) found that shrinking Arctic sea ice could lead to a northward shift of cyclone tracks and weaker Rossby wave activity in eastern China, resulting in a more stable atmosphere. Zou et al. (2017) found that continued Arctic sea ice loss together with more extensive snowfall in Eurasia could worsen ventilation in the East China Plain. The synoptic-scale variable most directly affecting Beijing haze is the strength of the East Asian winter monsoon (EAWM), which ventilates Beijing with clean air from the north. By analyzing $\mathrm{PM}_{2.5}$ observations in Beijing during the winters of 2010-2017, Cai et al. (2017) found that haze events are associated with weakened northerly wind at $850 \mathrm{hPa}$, weakened northwesterly wind at $500 \mathrm{hPa}$, and enhanced temperature difference between 250 and $850 \mathrm{hPa}$. Using climate projections for these three variables from the IPCC Coupled Model Intercompari- 
son Project Phase 5 (CMIP5) (Taylor et al., 2012) model ensemble, they inferred that the days conducive to severe haze events $\left(>150 \mu \mathrm{g} \mathrm{m}^{-3}\right.$ ) would increase by $50 \%$ by 2100 due to climate change under the business-as-usual Representative Concentration Pathway (RCP) 8.5 climate change scenario (Cai et al., 2017). In further simulations with a climate model, Li et al. (2018) specifically related these changes in the EAWM to increasing greenhouse gases.

Here we re-examine the effect of climate change on Beijing winter haze by bringing in several meteorological factors not adequately considered in previous work. First is the effect of relative humidity $(\mathrm{RH})$, which is not only an indicator of stagnation but also drives $\mathrm{PM}_{2.5}$ production through aqueous-phase heterogeneous chemistry (Y. S. Wang et al., 2014; Y. X. Wang et al., 2014; Woo and McNeill, 2015; Shen et al., 2017; Leung et al., 2018; Zhang et al., 2018). Second is the complexity of the relationship between Beijing haze and Arctic sea ice, which we will show reflects not the total amount of ice but its spatial distribution. Third is the role of sea surface temperatures (SSTs) in the Pacific and Indian Ocean, known to affect wintertime weather in the North China Plain (Annamalai et al., 2005; Kim et al., 2016). Fourth, as we will show, is the multidecadal variability in the relationships of Arctic sea ice and SSTs to the regional conditions conducive to Beijing haze. We conclude that the effect of climate change on Beijing haze is far more uncertain than reported in previous studies and most likely inconsequential for haze control strategies.

\section{Data}

We base our analysis on the 2010-2017 continuous record of $\mathrm{PM}_{2.5}$ available from the U.S. Embassy in Beijing. The measurements are done with a beta attenuation monitor at fixed RH (San Martini et al., 2015) (http://www.stateair.net/web/ historical/1/1.html, last access: March 2018). Li et al. (2018) have shown that this dataset can be considered representative of mean $\mathrm{PM}_{2.5}$ concentrations in Beijing by comparing it with observations from other 12 sites. For the in situ meteorological observations, we use RH and surface wind speed from the NOAA Global Summary of the Day (GSOD) network. For the vertical temperature gradient, we rely on the Integrated Global Radiosonde Archive (IGRA) (Durre et al., 2008). For the east-west and north-south wind velocities at 850 and $500 \mathrm{hPa}$, we use the National Centers for Environmental Prediction (NCEP) Reanalysis 1, mapped onto the $2.5^{\circ}$ grid resolution (Kalnay et al., 1996). Velocities are positive northward and eastward. For SSTs, we rely on the NOAA Extended Reconstructed SSTs (ERSST v4) (Huang, 2016). For the sea ice concentrations (SICs), we use Hadley Centre Sea Ice and Sea Surface Temperature dataset (HadISST) (Rayner et al., 2003). The SIC is unitless, ranging from 0 to 1 . The sea ice area is defined as the area of each grid cell multiplied by its SIC.
Relationship of Beijing $\mathrm{PM}_{2.5}$ with weather variables
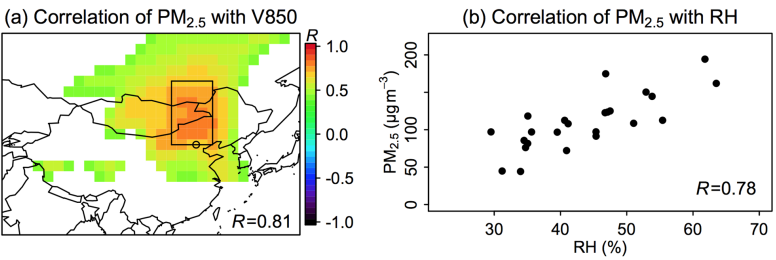

(c) Meteorological $\mathrm{PC} 1$ for $\mathrm{PM}_{2.5}$ prediction
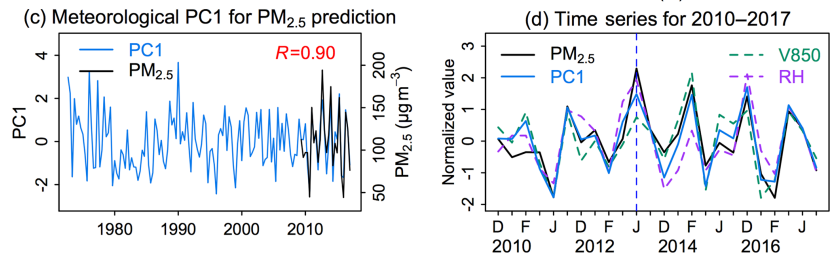

Figure 1. Relationships of wintertime monthly mean $\mathrm{PM}_{2.5}$ concentrations in Beijing (DJF 2010-2017 record) with local and regional meteorological variables. (a) Correlations with the $850 \mathrm{hPa}$ meridional wind velocity in Beijing and the surrounding region. The open circle denotes Beijing. The maximum correlation is for the rectangular box, which we use to define V850 in the text. The correlation coefficient $R$ of monthly $\mathrm{PM}_{2.5}$ and V850 in that box is shown inset. (b) Relationship with local relative humidity (RH) measured at Beijing Airport, with the correlation coefficient shown inset. (c) Time series of the first principal component (PC1) of V850 and RH for the 1973-2017 period (see Eq. 1 for definition of PC1). The time series of observed $\mathrm{PM}_{2.5}$ during 2010-2017 is also shown. The correlation coefficient of PC1 and $\mathrm{PM}_{2.5}$ during 2010-2017 is shown inset. (d) Monthly mean time series for 2010-2017 of PC1 and normalized $\mathrm{PM}_{2.5}$, V850, and $\mathrm{RH}$, where the normalization is relative to the 2010-2017 means.

To project the effects of climate change on $\mathrm{PM}_{2.5}$ air quality, we use meteorological fields from climate models participating in the Coupled Model Intercomparison Project Phase 5 (CMIP5) and following the RCP8.5 scenario (Taylor et al., 2012). We use an ensemble of 32 models that provide monthly values and 21 models that also provide daily values. The CMIP5 data are archived at a horizontal resolution of $\sim 200 \mathrm{~km}$, and the details of these models can be found in Table S2 in the Supplement.

\section{Relationship of Beijing haze to local and regional weather variables}

Figure 1a shows the correlations of DJF monthly mean $\mathrm{PM}_{2.5}$ in Beijing with the meridional wind velocity at $850 \mathrm{hPa}$ from the NCEP reanalysis (Kalnay et al., 1996). There is a strong relationship as previously pointed out by Cai et al. (2017). The wind is consistently from the north, and the corresponding velocity is negative (southward); therefore the correlation with $\mathrm{PM}_{2.5}$ is positive (high $\mathrm{PM}_{2.5}$ is associated with weak or northerly wind). Maximum correlation is for the rectangular domain to the north of Beijing, and we will refer to V850 in what follows as the mean meridional wind velocity at $850 \mathrm{hPa}$ within that domain. Figure $1 \mathrm{~b}$ shows in addition 

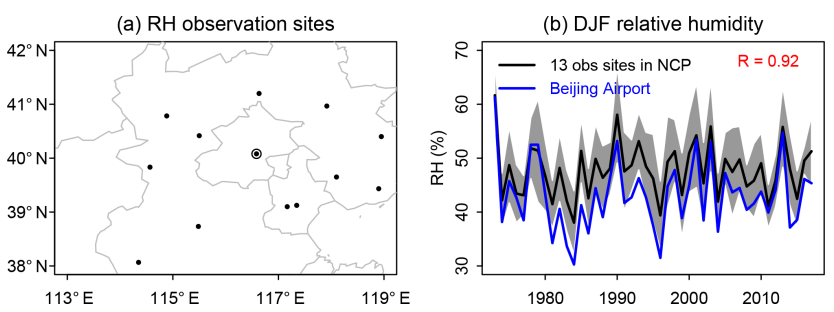

Figure 2. Representativeness of relative humidity $(\mathrm{RH})$ observed at Beijing Airport and used in this work for correlation to $\mathrm{PM}_{2.5}$. (a) Location of Beijing Airport and the 12 surrounding sites of the NOAA Global Summary Of the Day (GSOD) network in the North China Plain (NCP). (b) Time series of DJF 1973-2017 mean relative humidity (RH) at the Beijing Airport site and for the ensemble of the 13 NCP sites. Shaded area denotes 1 standard deviation. The correlation coefficient $(R)$ of RH at Beijing Airport with the North China Plain (NCP) average is 0.92 .

a strong correlation of monthly $\mathrm{PM}_{2.5}$ with local relative humidity measured at Beijing Airport (RH in what follows). We use the Beijing Airport measurement because the NCEP analysis is not reliable for relative humidity (Fig. S1). The Beijing Airport measurements of RH are regionally representative as shown by strong correlation $(R=0.92)$ with measurements from other sites in the North China Plain (Fig. 2). We find that other meteorological variables previously linked to winter haze, including the difference between the $500 \mathrm{hPa}$ zonal winds north and south of Beijing $\left(95-130^{\circ} \mathrm{E}, 47.5-\right.$ $55^{\circ} \mathrm{N}$ vs. $\left.120-145^{\circ} \mathrm{E}, 27.5-35^{\circ} \mathrm{N}\right)(\delta \mathrm{U} 500$, Fig. S2), and vertical potential temperature gradients between 925 and $1000 \mathrm{hPa}\left(\delta T_{925-1000}\right)$ (Zou et al., 2017), have lower correlations with monthly mean $\mathrm{PM}_{2.5}$ than V850 and RH (Fig. S3).

Figure $1 \mathrm{c}$ shows the correlation of Beijing $\mathrm{PM}_{2.5}$ with the first principal component (PC1) of monthly mean V850 and RH. PC1 is the sum of V850 and RH after the normalization of units:

$\mathrm{PC} 1=\frac{1}{\sqrt{2}}\left(\frac{\mathrm{V} 850-\mathrm{V} 850_{\text {mean }}}{\mathrm{V} 850_{\mathrm{SD}}}+\frac{\mathrm{RH}^{-\mathrm{RH}_{\text {mean }}}}{\mathrm{RH}_{\mathrm{SD}}}\right)$,

where $\mathrm{V} 850_{\text {mean }}$ and $\mathrm{RH}_{\text {mean }}$ refer to the temporal mean, and $\mathrm{V} 850_{\mathrm{SD}}$ and $\mathrm{RH}_{\mathrm{SD}}$ refer to the standard deviation. We find a much stronger correlation of $\mathrm{PM}_{2.5}$ with $\mathrm{PC} 1(R=0.90)$ than with either V850 $(R=0.81)$ or RH $(R=0.78)$. V850 and RH are moderately correlated $(R=0.60)$. PC1 includes information from both variables in a way that can better characterize the main weather mode related to the haze pollution. Figure 1d shows the 2010-2017 normalized time series of DJF monthly mean $\mathrm{PM}_{2.5}, \mathrm{~V} 850, \mathrm{RH}$, and $\mathrm{PC} 1$, illustrating how the relationship of $\mathrm{PM}_{2.5}$ with $\mathrm{PC} 1$ is much stronger than with either V850 or RH. We also conducted principal component analyses using additional meteorological variables including surface wind speed, $\delta$ U500, and $\delta T_{925-1000 \mathrm{hPa}}$, and find that the first principal components do not resolve additional $\mathrm{PM}_{2.5}$ variability (Table S1). The strong correlation of $\mathrm{PC} 1$ with $\mathrm{PM}_{2.5}$ has a clear physical ba- sis because weak winds correspond to stagnation events and high $\mathrm{RH}$ promotes chemical $\mathrm{PM}_{2.5}$ formation. In what follows we will use the $\mathrm{PC} 1$ of $\mathrm{V} 850$ and $\mathrm{RH}$ as meteorological proxy for $\mathrm{PM}_{2.5}$ in order to analyze longer historical records than the 2010-2017 period of $\mathrm{PM}_{2.5}$ observations and in order to make projections of $\mathrm{PM}_{2.5}$ response to future climate change.

Our PC1 predictor of $\mathrm{PM}_{2.5}$ shows large interannual variability over 1973-2017 but no significant trend (Fig. 1c), and neither do the principal components constructed from additional meteorological variables (Table S1, Fig. S4). Zou et al. (2017) previously defined a pollution potential index for the East China Plain $\left(30-41^{\circ} \mathrm{N}, 112-122^{\circ} \mathrm{E}\right)$ on the basis of surface wind speed and the temperature gradient between 925 and $1000 \mathrm{hPa}$, both taken from the NCEP reanalysis (Kalnay et al., 1996). They found a significant increase of this index during 1980-2017, driven by decreasing wind speed and increasing temperature gradient in the lower troposphere. However, the NCEP reanalysis trends for these two variables appear to be spurious. When using in situ observations from the 13 North China Plain sites, we find that the surface wind speed decreases from 1980 to early 2000s but then increases after 2005 (Fig. S5), in phase with the EAWM strength (Ding et al., 2014) that also increases after 2005. Overall the trend in surface wind speed during 1980-2017 is insignificant. The meteorological radiosonde data in the North China Plain show a significant decreasing temperature gradient between 925 and $1000 \mathrm{hPa}$ from 1993 to 2017 (Fig. S6a), in contrast to the NCEP data (Fig. S6b).

\section{Relationship of Beijing haze to Arctic sea ice and sea surface temperatures}

Previous studies have suggested that Arctic sea ice melting would worsen haze pollution in eastern China (Wang et al., 2015; Zou et al., 2017). But we find the correlation of the PC1 Beijing haze proxy with total Arctic sea ice area to be insignificant $(R=-0.08)$. This is consistent with Yin and Wang et al. (2017), who also found an insignificant relationship of North China Plain haze pollution in December with total Arctic sea ice. Instead, we find that the relationship of PC1 with SIC is more complicated and displays a dipole pattern, with locations shifting in different months (Figs. 3a-b, S7). Figure 3a shows the slopes of Arctic sea ice in the preceding autumn (September-October-November, SON) regressed onto $\mathrm{PC} 1$ in winter, displaying positive slopes in the Laptev Sea $\left(90-150^{\circ} \mathrm{E}\right)$ but negative slopes elsewhere. Here we define the SON $\triangle$ SIC as the difference of total sea ice area between regions with significant positive and negative slopes. The correlation coefficient of PC1 with SON $\triangle$ SIC is 0.60. Previous research has identified a dipole Arctic sea ice pattern in the SON and shown that this pattern can excite a stationary Rossby wave train propagating southeastward to Eurasia (Chen et al., 2014) with predictive capabil- 
Relationships of DJF PC1 with SSTs and SICs (1973-2017)

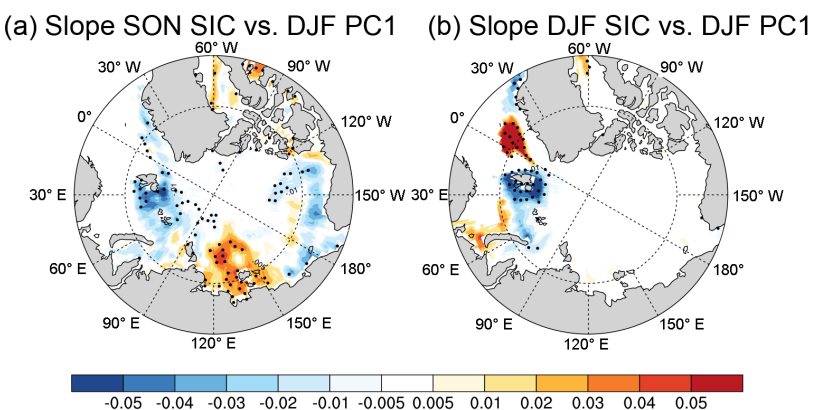

$\begin{array}{lll}\text { (c) Slope SON SST vs. DJF PC1 } & \text { (d) Slope DJF SST vs. DJF PC1 }\end{array}$

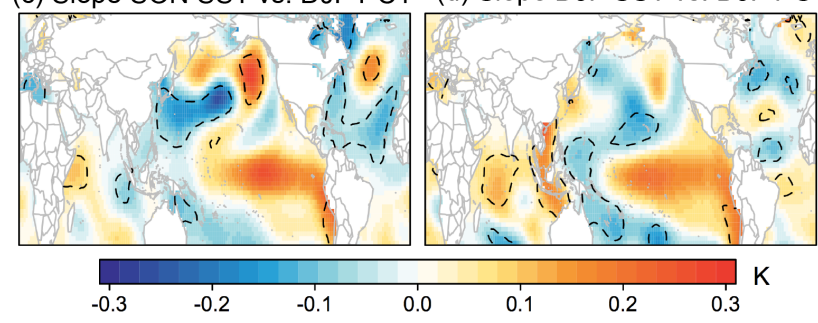

(e) Time series of $\mathrm{PM}_{2.5}, \mathrm{PC} 1$, and SST/SIC predicted PC1

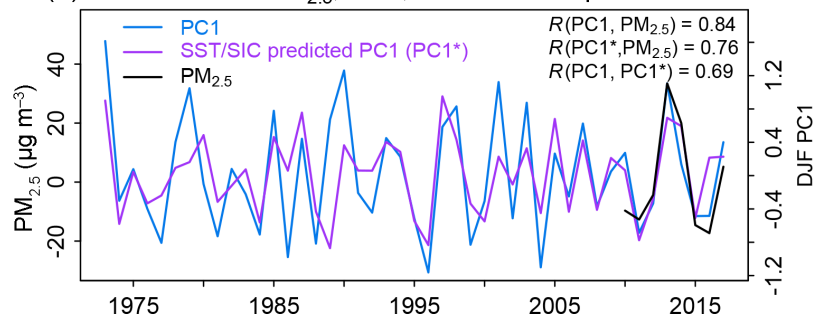

Figure 3. Relationships of sea ice concentrations (SICs) and sea surface temperatures (SSTs) with Beijing winter haze diagnosed from the first meteorological principal component PC1 (Eq. 1) for 1973-2017. The slopes of the linear regressions for SICs in the (a) preceding autumn and (b) current winter vs. normalized PC1 are shown. Grid boxes with statistically significant correlations $(p<0.1)$ are stippled. Panels $(\mathbf{c}-\mathbf{d})$ show the corresponding slopes of the linear regressions for SSTs. The dashed contour lines enclose regions in which correlations are statistically significant $(p<0.1)$. Panel (e) shows the time series of observed wintertime mean $\mathrm{PM}_{2.5}$ concentrations in Beijing, PC1, and the predicted PC1 (PC1*) from SST and SIC (see text). The correlation coefficients of different time series are shown inset. For all panels, data are detrended by subtracting the 7-year moving average. The correlation coefficient of PC1 with $\mathrm{PM}_{2.5}(R=0.84)$ is lower than in Fig. $1(R=0.90)$ because it is calculated here from seasonal rather than monthly average data.

ity for the EAWM (Chen et al., 2014; Sun et al., 2016) and for winter haze frequency in the North China Plain (Yin and Wang, 2016a).

Haze pollution in Beijing is also modulated by SST variability in the Pacific (Yin and Wang, 2016b) and Indian Ocean (Fig. 3c-d), implying that the projection of future haze at least needs to consider changes of both SSTs and SICs. Figure 3c shows the slopes of SSTs in the preceding autumn (SON) regressed onto the PC1 haze proxy in winter during 1973-2017. We see a dipole pattern over the North Pacific, with cool SST anomalies for the western Pacific and warm anomalies for the eastern Pacific. From autumn to winter the correlations shift to the tropics, with a dipole pattern of warm SST anomalies for the Indian Ocean and cool anomalies for the western tropical Pacific (Figs. 3d, S8). Yin and Wang (2016b) found that cool SSTs in the subtropical western Pacific in the previous autumn could excite a Rossby wave train that weakens the prevailing northerly wind over the North China Plain. Li et al. (2015) showed that anomalous southerly wind along the coast of eastern China could also be induced by a warm Indian Ocean, transporting moisture to eastern China. We also identify enhanced relative humidity across much of the eastern China associated with warmer SSTs in the Indian Ocean (Fig. S9). To characterize the SST dipole pattern in the North Pacific in Fig. $3 c$, we define SON $\Delta$ SST as the average SST difference between western Pacific and Northeast Pacific. Using these two metrics, SON $\triangle$ SST and SON $\triangle$ SIC, we can predict about $\sim 50 \%$ of the variance of $\mathrm{PC} 1$ one season in advance using a linear model. Using a 7-year moving average to detrend the time series yields a correlation coefficient of 0.69 between reconstructed and predicted PC1 during 1973-2017, and a correlation coefficient of 0.76 between observed $\mathrm{PM}_{2.5}$ and predicted PC1 based on a limited history during 2010 2017 (Fig. 3e).

However, we find that these relationships of PC1 with SST and SIC shift on timescales of decades, compromising their use to project future $\mathrm{PM}_{2.5}$ changes. Both V850 and RH over 1950-2017 can be obtained from the NCEP reanalysis, while local RH measurements in Beijing date back only to the mid1970s. However, we have little confidence in the NCEP RH because it is only weakly correlated with local measurements (Fig. S1), and so we focus on V850 going back to 1950. Figure $4 \mathrm{a}-\mathrm{b}$ show the slopes of SICs in the preceding SON regressed onto DJF V850 during 1950-1979 and 1980-2017. We choose the year 1980 as the boundary between these two timeframes because the SIC observations before 1980 are not validated with satellite observations (Rayner et al., 2003). Previous studies have also linked the EAWM with variations of the Arctic Oscillation (AO). As with Arctic sea ice, however, the EAWM-AO relationship displays large interdecadal variability, with a strengthening since the 1980s ( $\mathrm{Li}$ et al., 2014). The decadal oscillation of the EAWM-AO relationship could be attributable to the location of the East Asian jet stream (Li et al., 2014). Similarly, the relationship of DJF V850 and SSTs also displays very different dipole patterns during 1950-1976 and 1977-2017 (Fig. 4c-d), including a weaker relationship with the El Niño-Southern Oscillation (ENSO) in the more recent record. This result is consistent with previous studies that identified a weakened EAWMENSO relationship after the mid-1970s (Kim et al., 2016; Wang and He, 2012; He and Wang, 2013). Several mechanisms have been proposed to explain this, including a phase shift of the Pacific Decadal Oscillation (PDO) (Wang et al., 
Slopes of SON SST/SIC vs. DJF V850 in different periods

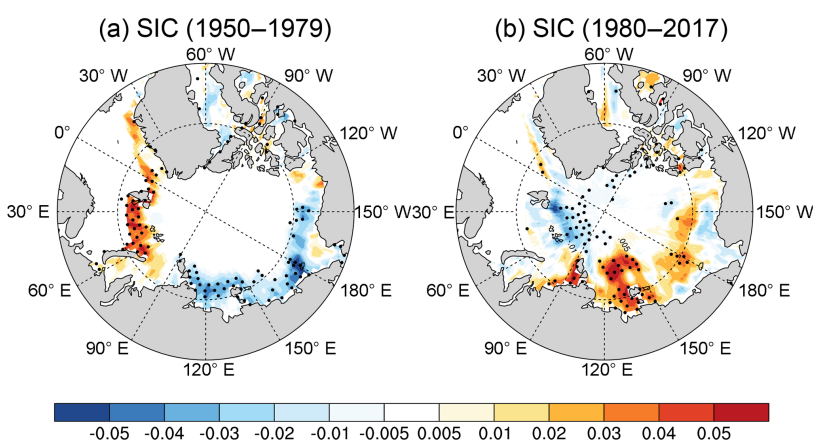

(c) SST (1950-1976)

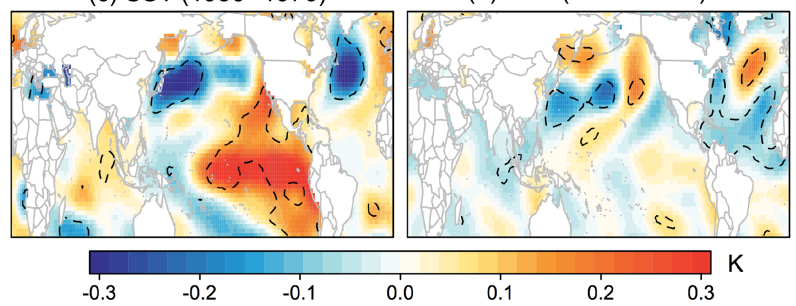

Figure 4. Multidecadal shifts in the relationships between the meridional wind over northern China in winter (V850) with sea ice concentrations (SICs) and sea surface temperatures (SSTs) in the preceding autumn (SON). The regression slopes of SON SICs vs. normalized DJF V850 during (a) 1950-1979 and (b) 19802017 are shown. Grid boxes with statistically significant correlations $(p<0.1)$ are stippled. Panels $(\mathbf{c}-\mathbf{d})$ show the same for SSTs. The dashed contour lines enclose regions in which correlations reach statistical significance $(p<0.1)$. For all panels, data are detrended by subtracting the 7 -year moving average.

2008), the combined effects of Atlantic Multidecadal Oscillation and PDO in modulating the North Pacific Oscillation (He and Wang, 2013), and the varying location and intensity of the northwest Pacific anticyclone combined with a Walker circulation between the eastern and central Pacific (Kim et al., 2016). Using the 20th century reanalysis, He and Wang (2013) found that this low-frequency oscillation in the EAWM-ENSO relationship has a period of 50 years, and that it may have recovered in the past decade as the PDO has shifted to a negative phase and the Walker circulation has strengthened.

Thus, we conclude that future climate projections of SIC or SSTs do not allow confident prediction of the meteorological conditions conducive to Beijing haze because the relationships of the haze with these variables are complicated and fluctuate on multidecadal scales, apparently in response to low-frequency climate modes. The relationship with SIC depends on a dipole structure in the sea ice, rather than the total amount of sea ice, so that there is no simple link between shrinking Arctic sea ice and increased haze pollution in Beijing.
2080-2099 vs. $2000-2019$ trends of DJF RH, V850, and predicted $\mathrm{PM}_{2.5}$ in RCP 8.5

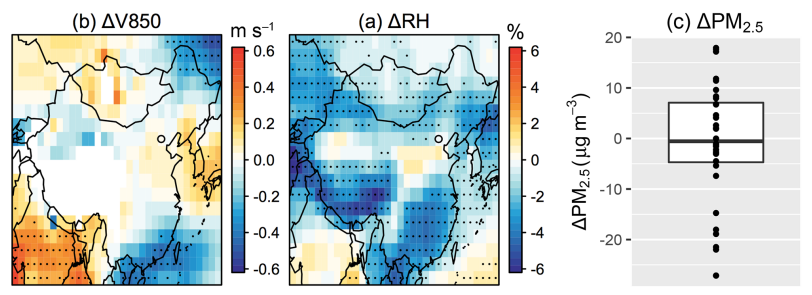

Figure 5. Projecting the effect of 21 st century climate change (2080-2099 vs. 2000-2019) on Beijing winter haze. Results are for mean wintertime changes $(\Delta)$ of (a) meridional wind velocity at $850 \mathrm{hPa}(\mathrm{V} 850)$ and (b) surface relative humidity (RH) in the RCP8.5 climate change scenario from an ensemble of 32 climate models on a $2^{\circ} \times 2.5^{\circ}$ grid (Table S2). Grid boxes in which more than $70 \%$ of the models show a consistent sign of change are stippled. The location of Beijing is indicated with a circle. (c) Predicted changes of mean wintertime $\mathrm{PM}_{2.5}$ in Beijing from individual CMIP5 models (symbols), using the first principal component of V850 and RH (PC1) as a proxy and assuming present-day emissions. The top and bottom of the box are the 25 th and 75 th percentile, and the centerline is the 50th percentile.

\section{Insignificant effect of 21st century climate change on Beijing haze}

The strong physical basis relating our PC1 meteorological proxy to Beijing haze suggests that it can be used to project the effect of future climate change. Figure $5 \mathrm{a}-\mathrm{b}$ shows mean 2080-2099 vs. 2000-2019 trends in 850 hPa meridional wind velocity (V850) and RH from the ensemble of 32 CMIP5 models following the RCP8.5 business-as-usual scenario. The $850 \mathrm{hPa}$ meridional wind shows no consistent trend over China (Fig. 5a), as also reported by Xu et al. (2016). We find a decrease of RH by $1 \%-6 \%$ across much of East Asia (Fig. 5b), likely due to (1) faster warming over land (Byrne and O'Gorman, 2013) and (2) enhanced subsidence at midlatitudes as a consequence of the expanding Hadley circulation (Lau and Kim, 2015). The RH changes in Beijing do not reach statistical significance, however. Using projected changes in PC1 from the individual CMIP5 models, together with the $\mathrm{PM}_{2.5}$ vs. $\mathrm{PC} 1$ relationship of Fig. 1c, we find that climate change alone would decrease the DJF mean $\mathrm{PM}_{2.5}$ in Beijing by $-0.68 \pm 11.7 \mu \mathrm{g} \mathrm{m}^{-3}$ from 2000-2019 to 20802099 , where the mean and standard deviation apply to the ensemble of CMIP5 models (Fig. 5c). The insignificant mean and the large spread imply little confidence in the projections from individual models including in the sign.

We pointed out previously how alternative principal component predictors of Beijing haze could be derived using additional meteorological variables (i.e., $\delta T_{925-1000}$, surface wind speed). We find that these alternative principal components similarly show no significant trend from 20002019 to 2080-2099. The associated mean changes in $\mathrm{PM}_{2.5}$ from the ensemble of CMIP5 models range from -1.40 to 


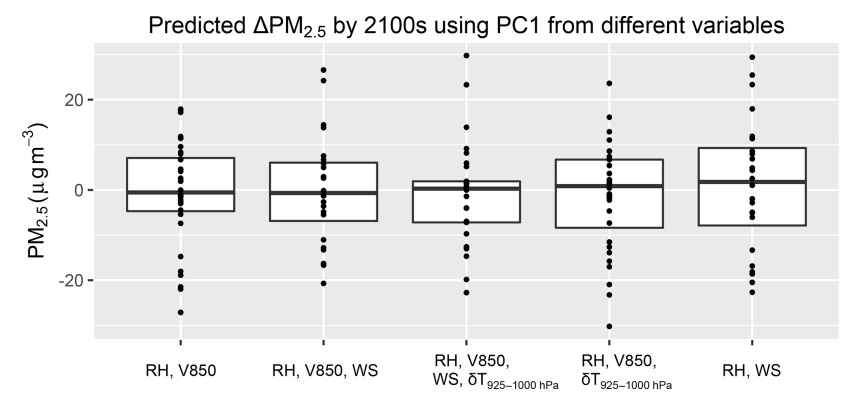

Figure 6. Same as Fig. 5c, but using PC1s constructed from five different combinations of meteorological variables as listed in Table S1. We do not include the two PC1s that use $\delta$ U500 (experiment no. 3 and no. 6 in Table S1). See text for more details.

$1.03 \mu \mathrm{g} \mathrm{m}^{-3}$ for the different principal components (Figs. 6, S10), or about $\pm 1 \%$ of mean $2010-2017$ concentrations.

Our results apply to monthly mean $\mathrm{PM}_{2.5}$ concentrations, but Pendergrass et al. (2018) used the same meteorological variables with an extreme value point process model to project the effect of climate change on the occurrence of severe wintertime $\mathrm{PM}_{2.5}$ pollution events $(24 \mathrm{~h}$ average $>300 \mu \mathrm{g} \mathrm{m}^{-3}$ ) in Beijing. They similarly find low V850 and high RH to be the two best predictor variables for these extreme haze events. They show no significant effect of climate change in the frequency of haze events for the RCP8.5 scenario, using the same ensemble of CMIP5 climate models as here, and a decrease for the alternative RCP4.5 scenario due to decreasing RH under low wind speed conditions. They conclude that climate change would most likely decrease the frequency of severe haze events in Beijing.

One remaining question is why our results are not consistent with Cai et al. (2017), who previously found a $50 \%$ increase by 2100 in the number of days conducive to severe Beijing haze events $\left(>150 \mu \mathrm{g} \mathrm{m}^{-3}\right)$, using 15 CMIP5 models applied to the RCP8.5 climate forcing scenario. They based their conclusions on projected increases in V850, increased temperature differences between 850 and $250 \mathrm{hPa}$ $\left(\delta T_{250-850}\right)$, and increases in the meridional gradient of the $500 \mathrm{hPa}$ zonal wind ( $\delta \mathrm{U} 500)$. We confirm these trends in $\delta T_{250-850}$ and $\delta \mathrm{U} 500$ in the more complete ensemble of 32 CMIP5 models, but do not find an increase in V850. Cai et al. (2017) showed that higher $\delta$ U500, characterized by weakened zonal flow south of Beijing but strengthened zonal flow north of Beijing, could lead to higher V850. We confirm this relationship both in the NCEP reanalysis during 20002019 (Fig. S2) and in the CMIP5 models for the 21st century (Fig. S11a), but the trend in $\delta$ U500 does not appear to drive a trend in V850 (Fig. S11b-c). Similarly, the trend in $\delta T_{250-850}$ does not appear to drive a trend in $\delta T_{925-1000}$ (Fig. S10a). Most importantly, Cai et al. (2017) did not consider RH as a predictor variable for the occurrence of extreme haze, even though it plays a critical role and is only moderately correlated with V850. Indeed, Pendergrass et al. (2018) showed that they could reproduce the increase in the frequency of extreme haze events found by Cai et al. (2017) by omitting RH as a predictor variable in their point process model, but that the resulting model did not properly fit the observed extreme value data.

\section{Conclusions}

Several recent studies have suggested that 21 st century climate change will greatly worsen the meteorological conditions leading to severe wintertime $\mathrm{PM}_{2.5}$ pollution in Beijing (winter haze). We find here that this is not the case.

Meridional wind velocity (V850) and relative humidity $(\mathrm{RH})$ are strong predictors of the variability of monthly mean $\mathrm{PM}_{2.5}$ in wintertime Beijing (Cai et al., 2017; Y. S. Wang et al., 2014; Y. X. Wang et al., 2014, Leung et al., 2018). We find that $\sim 80 \%$ of the $\mathrm{PM}_{2.5}$ variance can be explained by the first principal component (PC1) of these two variables, i.e., the sum of their normalized values. There is a strong physical basis for this relationship, as high V850 (weak northerly or southerly wind) is associated with stagnation, and high RH promotes chemical production of $\mathrm{PM}_{2.5}$. V850 and RH are only moderately correlated $(R=0.60)$. Thus PC1 is the better proxy for the meteorological conditions leading to Beijing haze. Principal components constructed from additional meteorological variables used in previous studies, including the $500 \mathrm{hPa}$ zonal wind dipole and vertical temperature gradient, do not improve predictability and show similar results.

Previous studies suggested that Arctic sea ice melting would worsen haze pollution in eastern China (Wang et al., 2015; Zou et al., 2017), but we find no correlation between total Arctic sea ice and the PC1 haze proxy. PC1 is instead significantly correlated to a dipole pattern in Arctic sea ice in the preceding autumn that is more difficult to interpret in terms of climate change. We find that PC1 is also associated with cool SSTs in the northwestern Pacific, consistent with a previous study (Yin and Wang, 2016b). However, we also find that these associations of PC1 with sea ice and SSTs shift and change sign on multidecadal timescales, possibly in concert with other climate oscillations. Thus it is not possible to use these large-scale climate variables in future projections of the effect of climate change on Beijing haze.

We went on to examine the 2000-2100 regional projections of V850, RH, and PC1 in the ensemble of IPCC CMIP5 models as a more direct inference of the effect of climate change on Beijing haze. We find that changes in $\mathrm{PM}_{2.5}$ inferred from changes in $\mathrm{PC} 1$ are inconsistent in sign across models and overall very small $(\sim 1 \%)$. It appears from our results that the effect of climate change on Beijing winter pollution is insignificant. 
Data availability. All datasets used in this study are publically accessible at https://doi.org/10.7910/DVN/BE5ZL9 (Shen, 2018).

Supplement. The supplement related to this article is available online at: https://doi.org/10.5194/acp-18-17489-2018-supplement.

Author contributions. LS and DJ designed the experiments and performed most of the analysis. LS and DJ prepared the manuscript with contributions from all coauthors.

Competing interests. The authors declare that they have no conflict of interest.

Acknowledgements. We thank Yufei Zou (Georgia Tech University) and Jintai Lin (Peking University) for fruitful discussion on the mechanism of large-scale climate patterns related to Beijing haze. This work was funded by the Harvard Global Institute (HGI).

Edited by: Bryan N. Duncan

Reviewed by: two anonymous referees

\section{References}

Annamalai, H., Liu, P., and Xie, S. P.: Southwest Indian Ocean SST variability: its local effect and remote influence on Asian monsoons, J. Climate, 18, 4150-4167, 2005.

Byrne, M. P. and O'Gorman, P. A.: Link between land-ocean warming contrast and surface relative humidities in simulations with coupled climate models, Geophys. Res. Lett., 40, 5223-5227, https://doi.org/10.1002/grl.50971, 2013.

Cai, W., Li, K., Liao, H., Wang, H., and Wu, L.: Weather conditions conducive to Beijing severe haze more frequent under climate change, Nat. Clim. Change, 7, 257-262, https://doi.org/10.1038/nclimate3249, 2017.

Chen, Z., Wu, R., and Chen, W.: Impacts of autumn Arctic sea ice concentration changes on the East Asian winter monsoon variability, J. Climate, 27, 5433-5450, 2014.

Ding, Y., Liu, Y., Liang, S., Ma, X., Zhang, Y., Si, D., Liang, P., Song, Y., and Zhang, J.: Interdecadal variability of the East Asian winter monsoon and its possible links to global climate change, J. Meteorol. Res., 28, 693-713, 2014.

Durre, I., Vose, R. S., and Wuertz, D. B.: Robust automated quality assurance of radiosonde temperatures, J. Appl. Meteorol. Climatol., 47, 2081-2095, 2008.

He, S. and Wang, H.: Oscillating relationship between the East Asian winter monsoon and ENSO, J. Climate, 26, 9819-9838, 2013.

Huang, B.: Further Exploring and Quantifying Uncertainties for Extended Reconstructed Sea Surface Temperature (ERSST) Version 4 (v4), J. Climate, 29, 3119-3142, 2016.

Kalnay, E., Kanamitsu, M., Kistler, R., Collins, W., Deaven, D., Gandin, L., Iredell, M., Saha, S., White, G., Woollen, J., and
Zhu, Y.: The NCEP/NCAR 40-year reanalysis project, B. Am. Meteorol. Soc., 3, 437-471, 1996.

Kim, J. W., An, S. I., Jun, S. Y., Park, H. J., and Yeh, S. W.: ENSO and East Asian winter monsoon relationship modulation associated with the anomalous northwest Pacific anticyclone, Clim. Dynam., 49, 1157-1179, 2016.

Lau, W. K. M. and Kim, K. M.: Robust Hadley Circulation changes and increasing global dryness due to $\mathrm{CO}_{2}$ warming from CMIP5 model projections, Proc. Natl. Acad. Sci. USA, 112, 3630-3653, 2015.

Leung, D. M., Tai, A. P. K., Mickley, L. J., Moch, J. M., van Donkelaar, A., Shen, L., and Martin, R. V.: Synoptic meteorological modes of variability for fine particulate matter $\left(\mathrm{PM}_{2.5}\right)$ air quality in major metropolitan regions of China, Atmos. Chem. Phys., 18, 6733-6748, https://doi.org/10.5194/acp-18-6733-2018, 2018.

Li, F., Wang, H. J., and Gao, Y. Q.: On the strengthened relationship between East Asian Winter Monsoon and Arctic Oscillation: a comparison of 1950-1970 and 1983-2012, J. Climate, 27, 50755091, 2014.

Li, K., Liao, H., Cai, W., and Yang, Y.: Attribution of anthropogenic influenceon atmospheric patterns conducive torecent most severe haze over easternChina, Geophys. Res. Lett. 45, 2072-2081, 2018.

Li, X., Li, J., and Li, Y.: Recent winter precipitation increase in middle-lower Yangtze River Valley since the late 1970s: a response to warming in tropical Indian Ocean, J. Climate, 28, 3857-3879, 2015.

Pendergrass, D. C., Shen, L., Jacob, D. J., and Mickley, L. J.: Predicting the impact of climate change on severe winter haze pollution events in Beijing using extreme value theory, in review, 2018.

Rayner, N. A., Parker, D. E., Horton, E. B., Folland, C. K., Alexander, L. V., Rowell, D. P., Kent, E. C., and Kaplan, A.: Global analyses of sea surface temperature, sea ice, and night marine air temperature since the late nineteenth century, J. Geophys. Res. 108, 4407, https://doi.org/10.1029/2002JD002670, 2003.

San Martini, F. M., Hasenkopf, C. A., and Roberts, D. C.: Statistical analysis of $\mathrm{PM}_{2.5}$ observations from diplomatic facilities in China, Atmos. Environ., 110, 174-185, https://doi.org/10.1016/j.atmosenv.2015.03.060, 2015

Shen, L.: Replication Data for: Insignificant effect of climate change on winter haze pollution in Beijing, https://doi.org/10.7910/DVN/BE5ZL9, Harvard Dataverse, V1, 2018.

Shen, L., Mickley, L. J., and Murray, L. T.: Influence of 2000-2050 climate change on particulate matter in the United States: results from a new statistical model, Atmos. Chem. Phys., 17, 43554367, https://doi.org/10.5194/acp-17-4355-2017, 2017.

Sun, C., Yang, S., Li, W., Zhang, R., and Wu, R.: Interannual variations of the dominant modes of East Asian winter monsoon and possible links to Arctic sea ice, Clim. Dynam., 47, 481-496, 2016.

Taylor, K. E., Stouer, R. J., and Meehl, G. A.: An overview of CMIP5 and the experiment design, B. Am. Meteorol. Soc., 93, 485-498, 2012.

Wang, H. and He, S.: Weakening relationship between East Asian winter monsoon and ENSO after mid-1970s, China Sci. Bull., 57, 3535-3540, 2012. 
Wang, H. J., Chen, H. P., and Liu, J. P.: Arctic sea ice decline intensified haze pollution in eastern China, Atmos. Ocean. Sci. Lett., $8,1-9,2015$

Wang, L., Chen, W., and Huang, R. H.: Interdecadal modulation of PDO on the impact of ENSO on the East Asian winter monsoon, Geophys. Res. Lett., 35, L20702, https://doi.org/10.1029/2008GL035287, 2008.

Wang, Y. S., Yao, L., Wang, L., Liu, Z., Ji, D., Tang, G., Zhang, J., Sun, Y., Hu, B., and Xin, J.: Mechanism for the formation of the January 2013 heavy haze pollution episode over central and eastern China, Sci. China Earth Sci., 57, 14-25, 2014

Wang, Y. X., Zhang, Q., Jiang, J., Zhou, W., Wang, B., He, K., Duan, F., Zhang, Q., Philip, S., and Xie, Y.: Enhanced sulfate formation during China's severe winter haze episode in Jan 2013 missing from current models, J. Geophys. Res.-Atmos., 119, 1042510440, https://doi.org/10.1002/2013JD021426, 2014.

WHO: WHO Air Quality Guidelines, World Health Organization, Geneva, Switzerland, 2006.

Woo, J. L. and McNeill, V. F.: simpleGAMMA v1.0 - a reduced model of secondary organic aerosol formation in the aqueous aerosol phase (aaSOA), Geosci. Model Dev., 8, 1821-1829, https://doi.org/10.5194/gmd-8-1821-2015, 2015.
$\mathrm{Xu}, \mathrm{M} ., \mathrm{Xu}, \mathrm{H}$. , and Ma, J.: Responses of the East Asian winter monsoon to global warming in CMIP5 models, Int. J. Climatol., 36, 2139-2155, 2016.

Yin, Z. and Wang, H.: Seasonal prediction of winter haze days in the north central North China Plain, Atmos. Chem. Phys., 16, 14843-14852, https://doi.org/10.5194/acp-16-14843-2016, $2016 a$.

Yin, Z. and Wang, H.: The relationship between the subtropical Western Pacific SST and haze over North-Central North China Plain, Int. J. Climatol., 36, 3479-3491, 2016b.

Yin, Z. and Wang, H.: Role of atmospheric circulations in haze pollution in December 2016, Atmos. Chem. Phys., 17, 11673 11681, https://doi.org/10.5194/acp-17-11673-2017, 2017.

Zhang, Q., Ma, Q., Zhao, B., Liu, X., Wang, Y., Jia, B., and Zhang, X.: Winter haze over North China Plain from 2009 to 2016: Influence of emission and meteorology, Environ. Pollut., 242, 13081318, 2018

Zou, Y., Wang, Y., Zhang, Y., and Koo, J. H.: Arctic sea ice, Eurasia snow, and extreme winter haze in China, Sci. Adv., 3, e1602751, https://doi.org/10.1126/sciadv.1602751, 2017. 